\title{
Daily Left Prefrontal Repetitive Transcranial Magnetic Stimulation in the Acute Treatment of Major Depression: Clinical Predictors of Outcome in a Multisite, Randomized Controlled Clinical Trial
}

\author{
Sarah H Lisanby*,', Mustafa M Husain ${ }^{2}$, Peter B Rosenquist ${ }^{3}$, Daniel Maixner ${ }^{4}$, Rosben Gutierrez ${ }^{5}$, \\ Andrew Krystal $^{6}$, William Gilmer ${ }^{7}$, Lauren B Marangell ${ }^{8}$, Scott Aaronson', Zafiris J Daskalakis ${ }^{10}$, \\ Randolph Canterbury' ', Elliott Richelson ${ }^{12}$, Harold A Sackeim ${ }^{13}$ and Mark S George ${ }^{14}$
}

'Division of Brain Stimulation and Therapeutic Modulation, Department of Psychiatry, Columbia University/New York State Psychiatric Institute, New York, NY, USA; ${ }^{2}$ Neurostimulation Research Lab, Geriatric Psychiatry Division, Department of Psychiatry, University of Texas Southwestern Medical Center, Dallas, TX, USA; ${ }^{3}$ Department of Psychiatry and Behavioral Medicine, Wake Forest University Medical Center, Winston-Salem, NC, USA; ${ }^{4}$ Department of Psychiatry, University of Michigan Medical Center, Ann Arbor, MI, USA; ${ }^{5}$ PsyCare Inc., Poways, CA, USA; ${ }^{6}$ Department of Psychiatry, Duke University Medical Center, Durham, NC, USA; ${ }^{7}$ Department of Psychiatry, Northwestern University Medical Center, Chicago, IL, USA; ${ }^{8}$ Department of Psychiatry, Baylor College of Medicine, Houston, TX, USA; ${ }^{9}$ Department of Psychiatry, Sheppard-Pratt Health System, Baltimore, MD, USA; ${ }^{10}$ Centre for Addiction and Mental Health, Toronto, ON, Canada; "'Department of Psychiatry, University of Virginia School of Medicine, Charlottesville, VA, USA; ${ }^{2}$ Department of Psychiatry, Mayo Clinic, Jacksonville, FL, USA; ${ }^{13}$ Department of Psychiatry, Columbia University, New York, NY, USA; ${ }^{14}$ Brain Stimulation Laboratory, Medical University of South Carolina, Charleston, SC, USA

Randomized controlled trials support the antidepressant efficacy of transcranial magnetic stimulation (TMS); however, there is individual variability in the magnitude of response. Examination of response predictors has been hampered by methodological limitations such as small sample sizes and single-site study designs. Data from a multisite sham-controlled trial of the antidepressant efficacy of TMS provided an opportunity to examine predictors of acute outcome. An open-label extension for patients who failed to improve provided the opportunity for confirmatory analysis. Treatment was administered to the left dorsolateral prefrontal cortex at 10 pulses per second 120\% of motor threshold, for a total of 3000 pulses per day. Change on the Montgomery-Asberg Depression Rating Scale after 4 weeks was the primary efficacy outcome. A total of 301 patients with nonpsychotic unipolar major depression at 23 centers were randomized to active or sham TMS. Univariate predictor analyses showed that the degree of prior treatment resistance in the current episode was a predictor of positive treatment outcome in both the controlled study and the open-label extension trial. In the randomized trial, shorter duration of current episode was also associated with a better outcome. In the open-label extension study, absence of anxiety disorder comorbidity was associated with an improved outcome, but duration of current episode was not. The number of prior treatment failures was the strongest predictor for positive response to acute treatment with TMS. Shorter duration of current illness and lack of anxiety comorbidity may also confer an increased likelihood of good antidepressant response to TMS.

Neuropsychopharmacology (2009) 34, 522-534; doi: I0.1038/npp.2008. I I 8; published online I3 August 2008

Keywords: transcranial magnetic stimulation; major depression; clinical trial; predictors; treatment resistance; TMS Study Group

\section{INTRODUCTION}

A growing number of controlled trials and meta-analyses (Burt et al, 2002; Holtzheimer et al, 2001; Martin et al, 2003;

*Correspondence: Dr SH Lisanby, Division of Brain Stimulation and Therapeutic Modulation, Columbia University Department of Psychiatry, New York State Psychiatric Institute, 1051 Riverside Drive Unit 21 , New York, NY 10032, USA, Tel: + I 212543 5568, Fax: + I 212543 6056, E-mail: slisanby@columbia.edu

Clinical trial posted on www.clinicaltrials.gov. Listing No. NCT 00104611 .

Received 28 December 2007; revised 3 July 2008; accepted II July 2008
Mitchell and Loo, 2006) support antidepressant effects of transcranial magnetic stimulation (TMS). However, not all studies are positive (Boutros et al, 2002; Cohen et al, 2003; Hansen et al, 2004; Hausmann et al, 2004; Loo et al, 1999; Loo et al, 2003; Mosimann et al, 2004) and earlier studies were hampered by small sample sizes and other limitations. A recent meta-analysis argues that the improved design (dose, length of treatment) of recent studies (Avery et al, 2006; Fitzgerald et al, 2003, 2006) is associated with larger treatment effects than work before 2000 (Gross et al, 2007). Consistent with this, we found TMS to be safe and efficacious in a pivotal randomized controlled trial of 301 
patients with major depression who had failed to benefit from at least one adequate antidepressant treatment in the current episode (O'Reardon et al, 2007). In an open-label extension study of those who did not improve in the randomized phase, open treatment with active TMS for 6 weeks resulted in significant improvement (42\% response rate for those who had failed to respond to sham, and $26 \%$ response rate in those who had failed to respond to active TMS; Avery et al, 2008). Identifying patient- and treatmentrelated factors influencing outcome would aid patient selection. The present study addresses factors related to response in this pivotal trial.

Among the most consistently reported predictors of antidepressant response is treatment resistance (Prudic et al, 1996a; Rush et al, 2006). The Sequenced Treatment Alternatives to Relieve Depression $\left(\mathrm{STAR}^{\star} \mathrm{D}\right)$ trial found remission rates drop from 28 to $6.9 \%$ with successive levels of treatment nonresponse (Rush et al, 2006). Other studies suggest depressive subtype (Paykel, 1972; Simpson et al, 1976), history and course of the illness (Keller et al, 1984, 1986; Trivedi et al, 2006), presence of Axis I or Axis II comorbidity, particularly anxiety (Hirschfeld et al, 1986; Trivedi et al, 2006), medical comorbidity (Hirschfeld et al, 1986; Trivedi et al, 2006), age (Dew et al, 1997; Gildengers et al, 2005), and polymorphisms affecting serotonin and glutamate neurotransmission (McMahon et al, 2006; Paddock et al, 2007) may influence response.

Patient-related factors emerging as being related to response to TMS include duration of current episode (Brakemeier et al, 2007; Holtzheimer et al, 2004), medication resistance (Brakemeier et al, 2007; Fregni et al, 2006), and age (Figiel et al, 1998; Fregni et al, 2006; Manes et al, 2001; Mosimann et al, 2002, 2004; Su et al, 2005). Fregni et al (2006) reported that younger age and less prior treatment resistance was associated with better response to TMS. Similarly, Brakemeier et al (2007) found that the least treatment-resistant patients showed the greatest clinical benefit. They also noted that baseline sleep disturbances predicted benefit from TMS.

Treatment-related factors influencing antidepressant response with TMS include stimulation intensity, frequency, number of pulses administered, and duration of the treatment course (Gershon et al, 2003; Padberg et al, 2002; Sachdev et al, 2002). Increasing the distance from the coil to the target cortex decreases the intensity of the stimulation reaching the brain, which is negatively correlated with antidepressant response and with the degree of stimulation-induced brain activation (Kozel et al, 2000; Mosimann et al, 2002; Nahas et al, 2001). The impact of atrophy on coil-to-cortex distance has been posited to contribute to reduced efficacy in the elderly (Figiel et al, 1998; Fregni et al, 2006; Manes et al, 2001; Mosimann et al, 2002, 2004; Su et al, 2005). Adjusting dose to overcome atrophy may result in better effects in the elderly (Nahas et al, 2004). Other treatment factors related to neurophysiological responses to TMS include coil and stimulator type, waveform shape and polarity, coil position, and orientation relative to target cortex (Davey and Epstein, 2000; Kammer et al, 2001a,b; Maccabee et al, 1998; Thielscher and Kammer, 2004). Even when these factors are held constant, considerable variability in neurophysiological responses to TMS has been described (Wassermann,
2002). Regional brain activation has been associated with differential response to high- $v s$ low-frequency TMS (Kimbrell et al, 1999), suggesting that the state of the circuitry targeted by TMS may affect outcome.

We examined candidate predictor variables in our recently completed, large multisite sham-controlled randomized clinical trial in medication-free unipolar depressed patients resistant to at least one antidepressant medication trial in the current episode (O'Reardon et al, 2007). Several potential predictors were held constant by the trial design, therefore we focused on those patient and treatment measures that contained sufficient variability to meaningfully assess their influence on clinical outcome. On the basis of the most consistent observations seen in earlier work with TMS and with other antidepressant treatments, we predicted that less medication resistance, younger age, and shorter illness duration would be associated with superior antidepressant efficacy of TMS.

\section{MATERIALS AND METHODS}

\section{Study Overview}

A randomized controlled trial of the antidepressant efficacy of TMS in unipolar depression was conducted at 23 clinical sites in the United States $(N=20)$, Australia $(N=2)$, and Canada $(N=1)$ (O'Reardon et al, 2007). Active enrollment occurred between January 2004 and August 2005. The study was a double-masked randomized controlled clinical trial designed to examine the efficacy of the Neuronetics NeuroStar TMS Therapy System compared to a sham TMS treatment condition. An open-label trial that followed the same treatment sequence as the randomized controlled trial was available for all patients who: (1) participated in the first study for at least 4 weeks and (2) had not received significant clinical benefit from their randomized assignment (Avery et al, 2008). The criterion defining failure of clinical benefit in the randomized controlled trial was applied in a blinded manner (ie investigators and patients were unaware of the criterion for eligibility for enrollment in the open-label extension study). The specific criterion to determine eligibility for entry into the open-label extension study was failure to achieve at least a $25 \%$ improvement in total score on the 17-item Hamilton Depression Rating Scale (HAMD17) compared to baseline assessment. During the entire clinical program, the blinded treatment assignment was not revealed until all patients had completed all treatments.

\section{Participants}

A complete description of the inclusion and exclusion criteria for participating patients is described elsewhere (O'Reardon et al, 2007). All patients met DSM-IV diagnostic criteria for unipolar, nonpsychotic major depressive disorder, confirmed by the Structured Clinical Interview for Diagnosis (IV). Patients were moderately to severely ill by symptom measures at baseline and moderately to severely resistant to pharmaceutical antidepressant treatment in the current illness episode as measured by the Antidepressant Treatment History Form (ATHF; Prudic et al, 1996b). The ATHF is a manualized, reliable, and validated method of 
rating the adequacy of antidepressant treatment trials. Use of the ATHF has demonstrated that for each adequate antidepressant treatment trial, a patient has usually experienced an average of four treatment attempts. Subjects with risk factors for seizure (eg prior seizure history) were excluded.

\section{TMS Treatment Parameters}

Each TMS treatment session consisted of a fixed-dose parameter set involving stimulation at $120 \%$ of the patient's observed motor threshold (MT), with a repetition rate of 10 pulses per second $(10 \mathrm{~Hz})$. Stimulation trains were $4 \mathrm{~s}$ in duration, followed by a $26 \mathrm{~s}$ intertrain interval, for a total of 40 pulses for each pulse train. A total of 75 pulse trains, or a total of 3000 pulses, were delivered in each treatment session to the left dorsolateral prefrontal cortex (DLPFC), defined as the site $5 \mathrm{~cm}$ anterior to the optimal area for stimulating the thumb.

Motor thresholds were performed via visual twitch in the contralateral hand muscle at the beginning of each treatment week or when indicated in the opinion of the clinical investigator. Complete details of cross-center training in study procedures, including MT determination and TMS delivery, may be found in Demitrack and Lisanby (2008). Briefly, training and verification of competence in MT determination was established before first treatment, and then periodic on-site visual observation of treatment technique was conducted for the duration of this study by the study monitors who traveled to each site. Reliability had to be demonstrated by each TMS operator on the determination of MT, selection of treatment site, and delivery of the treatment session following a detailed study manual and TMS device operator's manual (Demitrack and Lisanby, 2008).

\section{Adverse Event Reporting and Other Safety Assessments}

Safety results have been presented in detail elsewhere (Janicak et al, 2008; O'Reardon et al, 2007). Adverse events were obtained at each treatment visit by spontaneous verbatim report from the patient and coded by body system and preferred term using the current version of the Medical Dictionary for Regulatory Activities. All adverse events were assessed by the investigator with regard to their potential causal relationship to the study device (five-tiered assessment) and also by their clinical severity (three-tiered assessment). All serious adverse events were separately described.

During active stimulation, the operation of the device produces an audible clicking sound. All patients and investigative personnel present in the treatment room were required to use earplugs meeting a minimum standard of $30 \mathrm{~dB}$ protection. Air conduction auditory threshold was assessed utilizing the Micro Audiometer Earscan ${ }^{\mathrm{TM}}$ device at baseline, week 4, and week 6 during the acute treatment phase.

Cognitive function was assessed for global cognitive function, immediate and delayed recall, and long-term memory. The instruments used were the Mini Mental Status Exam, the Buschke Selective Reminding Test, and the Autobiographical Memory Interview-Short Form. These measures were obtained at baseline, week 4, and week 6 during the acute treatment phase.

\section{Summary of Candidate Predictor Variables}

Categorical variables included age, gender, duration of current illness episode, the presence of anxiety disorder as a comorbid illness, course of illness (single episode $v s$ recurrent), treatment resistance status in current episode (dichotomized as one $v s$ more than one adequate trial in the current episode), employment status, and the presence an atypical major depression. Continuous variables included Montgomery-Asberg Depression Rating Scale (MADRS) total score baseline symptom severity, and baseline MT.

\section{Statistical Analysis}

Efficacy analyses in the original randomized controlled trial were performed on the intent-to-treat sample of all evaluable patients, defined in the protocol as those with a baseline and at least one post-baseline observation available for analysis (O'Reardon et al, 2007). All analyses were conducted in a last-observation carried forward manner. A complete description of the prespecified statistical analysis methods used in the original randomized controlled trial is discussed in detail elsewhere (O'Reardon et al, 2007).

In this report, we used an exploratory statistical approach to examine the impact of selected predictors on clinical efficacy. As described in the sections above, there are several explanatory variables that may be plausibly expected to influence outcome based on prior literature reports. Data were analyzed using an analysis of covariance model. The explanatory variables in the model were the clinical predictor (either categorical or continuous), treatment group (active TMS or sham TMS assignment in the randomized controlled study), and the interaction term for the clinical predictor and treatment group. For the open-label study, the treatment assignment, and the interaction term were excluded, as this was an open-label crossover trial, and hence the two subgroups (Extended Active TMS and Sham-to-TMS treatment conditions) no longer represented randomized patient cohorts. However, we present the analyses for the pooled sample in the open-label study for reference comparison to the individual treatment group results in that study. In all analyses, the dependent variable was the change from baseline value for the primary efficacy measure (MADRS total score). For the randomized controlled trial the primary efficacy time point was specified at week 4 , and for the open-label study at week 6 of the acute treatment phase. In the randomized controlled trial, for any predictor where the $p$-value for the interaction term with treatment was less than the a priori designated threshold value $(p<0.10)$ analyses were conducted for each treatment group independently, using the specified clinical predictor as the only factor in the model. In the openlabel trial, the separate results of the univariate analyses in each the two treatment groups were used to draw conclusions regarding clinically interesting predictor-outcome relationships, again, using a threshold $p<0.10$ as the criterion of note. For both studies, results from these univariate analyses provided the necessary background to conduct further multivariate analyses on the candidate explanatory variables of statistical interest to understand the interaction of the 
proposed clinical predictors and their collective effect on clinical response. All analyses were conducted using SAS (version 8.02) on the Windows XP platform.

\section{RESULTS}

\section{Study Population Characteristics}

At entry into the randomized controlled trial, the active $(n=155)$ and sham $(n=146)$ groups did not significantly differ in age, gender, ethnicity, depression history (whether single episode or recurrent course), duration of current episode, presence of comorbid psychiatric disorders, or baseline symptom severity (Table 1 ). A total of 164 patients (54.5\% of the total sample) had received one antidepressant treatment trial of adequate dose and duration in the current episode, with the remainder of the patients receiving from two to four adequate treatment trials. Among those patients with one adequate antidepressant exposure, the median number of antidepressant treatment attempts that did not meet rigorous ATHF criteria for adequacy was 4, with a range of attempts from 1 to 23 different antidepressants.

A total of 158 patients who did not benefit from their randomized assignment in the controlled study elected to

Table I Summary of Demographic Characteristics, Illness Course and Symptom Severity in the Evaluable Study Population: Randomized Controlled Trial

Overall Evaluable Study Population $(\mathrm{N}=30 \mathrm{I})$

P-Value

\section{Variable Name}

Age in Years mean (SD)

Gender

$N(\%)$ Female

Ethnic origin N (\%)

Caucasian

All other

Depression history N (\%)

Single episode

Recurrent

Duration of current episode

Length in months [mean (SD)]

$<2$ years $N(\%)$

$\geqslant 2$ years $N(\%)$

Secondary diagnoses N (\%)

None

Any anxiety disorder

Prior antidepressant treatment

Number of antidepressant treatment attempts in current illness episode

$$
\begin{aligned}
& \text { Mean (SD) } \\
& \text { Median (range) }
\end{aligned}
$$

Number of doses/duration adequate antidepressant treatments in current episode

$$
\text { Mean (SD) }
$$$$
\text { Median (range) }
$$

Baseline symptom severity (mean (SD))

MADRS total score

HAMD24 total score

HAMD 17 total score

IDS-SR total score

CGl-severity total score

$$
\begin{array}{r}
5.5(3.4) \\
5(1.18) \\
1.6(0.9) \\
1(1.7) \\
32.6(5.3) \\
30.7(3.9) \\
22.6(2.3) \\
42.0(9.4) \\
4.7(0.6)
\end{array}
$$

0.201

$9(6.2)$

$137(93.8)$

0.611

$13.2(9.5)$
$123(84.2)$
$23(15.8)$

0.112

$104(71.2)$

$42(28.8)$

0.112
$5.4(3.6)$

$5(1,23)$

I.7 (0.8)

I $(1,4)$

$32.9(5.6)$

0.476

0.803

0.325

0.197

0.871 
participate in the open-label extension study. This subset did not differ significantly in demographic or clinical features from the overall sample of 301 enrollees who were initially enrolled into the controlled trial (data not shown). Patients entering the open-label study who received active TMS in the controlled trial are referred to as the 'Extended Active TMS' group, whereas those who received sham in the controlled trial are referred to as the 'Sham to TMS' group. The Extended Active TMS and the Sham to TMS groups did not differ significantly in age, gender, ethnicity, depression history, presence of comorbid psychiatric disorders, or baseline symptom severity (data reported elsewhere; Avery et al, 2008). The Extended Active TMS group was more likely to have a current episode longer than 24 months than the Sham to TMS group (26.0 vs 12.9\%, $p<0.04$, data reported elsewhere; Avery et al, 2008).

\section{Analysis of the Influence of Baseline Candidate Predictors on Outcome to Acute Treatment: Randomized Controlled Trial}

Among the categorical variables examined as predictors in the randomized controlled trial, treatment resistance history in the current episode $(p=0.021)$ and duration of current episode $(p=0.069)$ showed an interaction with treatment arm assignment at the assigned threshold of $p<0.10$ (Table 2). Further analysis of the impact of the identified variables within each treatment arm showed a significant effect for treatment resistance history in the current episode $(p=0.067)$ and duration of current episode $(p=0.015)$ in the active TMS treatment arm only. Specifically, active TMS-treated patients who failed to benefit from one adequate antidepressant treatment in the current episode showed significantly greater improvement in MADRS and HAMD24 total scores than those patients who had failed 2-4 adequate trials (Figure 1). There was no statistically significant influence of these variables on clinical outcome in sham-treated patients.

For the continuous variables, neither candidate variable exceeded the specified threshold level of significance at $p<0.10$.

A multivariate model using all two-way interactions among the predictor variables under the univariate outcomes analysis described above provided no meaningful alternative model to explain efficacy outcome than was apparent in the univariate results. Of note, there was not a significant interaction between duration of current episode and treatment resistance.

\section{Analysis of the Influence of Baseline Candidate Predictors on Outcome to Acute Treatment: Open-Label Extension Trial}

In contrast to the controlled trial, the treatment groups within the open-label study do not represent randomized assignments. Therefore, the interaction term of the predictor variable with treatment group was ignored, and only the univariate analyses, which explored evidence for a main effect of the predictor variable within either the Extended Active TMS or the Sham to TMS groups separately, were inspected. Using this methodology, in the Sham to TMS group, a reduced incidence of comorbid anxiety disorder $(p=0.005)$, less treatment resistance in current episode

Table 2 Univariate Analyses of Candidate Clinical Variables Evaluated as Predictors of Outcome with Acute Treatment (MADRS Total Score Change from Baseline): Randomized Controlled Trial

\begin{tabular}{|c|c|c|c|}
\hline Variable name & Variable definition & $\begin{array}{l}\text { p-value (interaction of } \\
\text { predictor variable and } \\
\text { treatment group) }\end{array}$ & Direction of effect on outcome \\
\hline \multicolumn{4}{|l|}{ Categorical } \\
\hline Age & $\geqslant 55$ years $v s<55$ years & 0.590 & - \\
\hline Gender & Male vs female & 0.936 & - \\
\hline Duration of current episode & $\leqslant 2$ years vs $>2$ years & 0.069 & $\begin{array}{l}\text { Greater effect for illness }<2 \text { years, } \\
(P=0.015, \text { active arm only })\end{array}$ \\
\hline Comorbid anxiety disorder & Any anxiety disorder vs none & 0.420 & - \\
\hline Course of illness & First episode vs recurrent illness & 0.862 & - \\
\hline $\begin{array}{l}\text { Treatment resistance (current } \\
\text { episode) }\end{array}$ & $\begin{array}{l}\text { One adequate treatment in current } \\
\text { episode vs more than one }\end{array}$ & 0.021 & $\begin{array}{l}\text { Superior outcome for one adequate } \\
\text { treatment group, ( } P=0.067 \text {, active } \\
\text { arm only) }\end{array}$ \\
\hline Employment status & Employed full or part time vs unemployed & 0.100 & - \\
\hline Atypical depression & Defined by IDS-SR criteria & 0.159 & - \\
\hline \multicolumn{4}{|l|}{ Continuous } \\
\hline Baseline symptom severity & MADRS total score at baseline & 0.774 & - \\
\hline Baseline motor threshold & $\begin{array}{l}\text { Motor threshold (\% machine output) at } \\
\text { baseline }\end{array}$ & 0.108 & - \\
\hline
\end{tabular}

Variables indicated in bold demonstrated a significant predictor variable $\times$ treatment arm interaction effect $(P<0.10)$.

- No statistically different benefit at the specified level in either treatment arm.

Please see text for further discussion of within treatment arm results and direction of effect on outcome. 

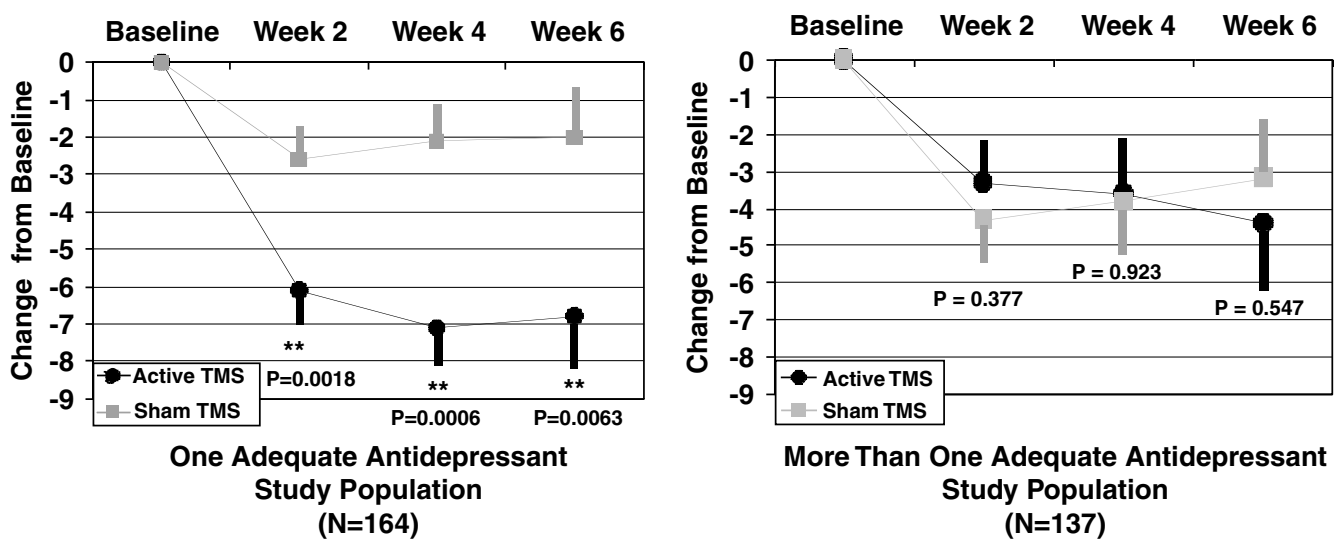

Figure I MADRS total score change from baseline (week 4) in intent-to-treat evaluable study population of patients with one adequate antidepressant treatment in current episode.

( $p=0.051)$, and higher symptom severity at entry $(p=0.024, r=-0.25)$ were associated with greater clinical benefit (Tables 2 and 3 ). In the Extended TMS group, a single illness episode $(p=0.021)$, female gender $(p=0.038)$, and a lower baseline MT $(p=0.054$, Pearson's $r=+0.23)$ were associated with greater clinical benefit (Table 3 ). Taking the pooled sample of both Extended Active TMS and Sham to TMS groups, only the absence of anxiety disorder $(p=0.007)$ and higher symptom severity at entry $(p=0.037)$ were associated with outcome. No meaningful multivariate model could be identified as an alternative explanatory model.

\section{Demographic and Clinical Features of Patients with Treatment Resistance to One Adequate Antidepressant Treatment in the Current Illness Episode Compared to the Remaining Patient Population}

Among the pattern of candidate predictor variables examined, prior treatment resistance history in the current episode showed the most consistent effect. In particular, failure to benefit from one adequate treatment in the current episode predicted outcome to short-term treatment (ie through 4 or 6 weeks of active TMS), as demonstrated in the active TMS-treated patients in the randomized controlled trial, and similarly in the Sham to TMS patient group in the open-label study. In patients treated for longer than 6 weeks, ie the Extended TMS group in the open-label study, this predictive effect of prior treatment resistance was not observed. Because of the apparent consistency of this effect within these studies and in the prior literature, we further examined the subgroup of patients who had failed to benefit from one adequate antidepressant treatment in the current episode, and compared them to the remaining patients on demographic characteristics, illness history, and clinical features (Tables 4 and 5).

At entry to the randomized controlled trial, patients who had failed to receive benefit from one adequate antidepressant treatment in current episode and who were assigned to sham were older by an average of 3 years than those assigned to active TMS (51.9 \pm 9.6 vs $48.6 \pm 10.8$, respectively, $p<0.039$ ), but they did not differ on other measured demographic or clinical variables. In the two treatment groups within the open-label trial, a similar small difference in age was noted between the Extended Active TMS and Sham to TMS groups within the cohort of patients who had one adequate antidepressant exposure in the current episode $(49.5 \pm 10.1$ vs $54.2 \pm 7.8$, respectively, $p<0.023)$.

Acute Efficacy Outcomes in Patients with Treatment Resistance to One Adequate Antidepressant Treatment in the Current Illness Episode Compared to the Remaining Patient Population

As noted above, patients who failed to receive benefit from one adequate antidepressant treatment in the current episode and were assigned to the active TMS treatment condition in the randomized controlled trial showed a statistically significantly superior outcome compared to the sham TMS-treated control study group. This outcome was evident on both MADRS and HAMD24 total scores (Figure 1).

Patients with an ATHF score of 1 (which corresponds to one adequate antidepressant treatment trial and a median of four treatment attempts in current episode) showed significant reductions in MADRS at weeks 2, 4, and 6 $(p<0.0018,0.0006$, and 0.0063 , respectively; Figure 1$)$. The remainder of the sample, with ATHF scores 2-4 (corresponding to 2-4 adequate treatment attempts in the current episode), failed to show a significant difference between active and sham. Similar effects were observed in the HAMD24 ratings. The effect size for active $v s$ sham TMS in the subset with an ATHF score of 1 was 0.83 (confidence interval $0.20-1.48$ ), whereas the effect size for the subset with ATHF scores of 2-4 was 0.42 (confidence interval -0.30 to 1.15$)$.

\section{DISCUSSION}

We report that a lower degree of medication resistance in the current episode predicts better antidepressant response to TMS. This finding is in line with prior reports that medication resistance was a predictor of response to medications (Rush et al, 2006), ECT (Prudic et al, 1996a), and TMS (Brakemeier et al, 2007; Fregni et al, 2006). Patients who failed to respond to sham TMS and were 
Table 3 Univariate Analyses of Candidate Clinical Variables Evaluated as Predictors of Outcome with Acute Treatment (MADRS Total Score Change from Baseline): Open-label Trial

\begin{tabular}{|c|c|c|c|c|c|c|c|}
\hline Variable name & Variable definition & $\begin{array}{c}\text { Pooled study } \\
\text { sample } p \text {-value } \\
\text { (main effect for } \\
\text { variable) }(N=158)\end{array}$ & $\begin{array}{l}\text { Direction of } \\
\text { effect }\end{array}$ & $\begin{array}{l}\text { Extended TMS } \\
\text { group } p \text {-value } \\
\text { (main effect for } \\
\text { variable) }(N=73)\end{array}$ & $\begin{array}{l}\text { Direction of } \\
\text { effect }\end{array}$ & $\begin{array}{l}\text { Sham to TMS } \\
\text { group p-value } \\
\text { (main effect for } \\
\text { variable) }(N=85)\end{array}$ & $\begin{array}{l}\text { Direction of } \\
\text { effect }\end{array}$ \\
\hline \multicolumn{8}{|l|}{ Categorical } \\
\hline Age & $\begin{array}{l}\geqslant 55 \text { years vs }<55 \\
\text { years }\end{array}$ & 0.296 & - & 0.362 & - & 0.364 & - \\
\hline Gender & Male vs female & 0.124 & - & 0.038 & $\begin{array}{l}\text { Superior effect for } \\
\text { females }\end{array}$ & 0.676 & - \\
\hline Duration of current episode & $\leqslant 2$ years vs $>2$ years & 0.955 & - & 0.987 & - & 0.799 & - \\
\hline $\begin{array}{l}\text { Comorbid anxiety } \\
\text { disorder }\end{array}$ & $\begin{array}{l}\text { Any anxiety } \\
\text { disorder vs none }\end{array}$ & 0.007 & $\begin{array}{l}\text { Superior effect } \\
\text { for no } \\
\text { comorbid } \\
\text { anxiety } \\
\text { disorder }\end{array}$ & 0.405 & - & 0.005 & $\begin{array}{l}\text { Superior effect for } \\
\text { no comorbid } \\
\text { anxiety disorder }\end{array}$ \\
\hline Course of illness & $\begin{array}{l}\text { First episode vs } \\
\text { recurrent illness }\end{array}$ & 0.386 & - & 0.021 & $\begin{array}{l}\text { Superior effect for } \\
\text { single episode }\end{array}$ & 0.408 & - \\
\hline $\begin{array}{l}\text { Treatment resistance } \\
\text { (current episode) }\end{array}$ & $\begin{array}{l}\text { One adequate } \\
\text { treatment in } \\
\text { current episode vs } \\
\text { more than one }\end{array}$ & 0.160 & - & 0.885 & - & $0.05 I$ & $\begin{array}{l}\text { Superior effect for } \\
\text { one adequate } \\
\text { treatment in } \\
\text { current episode }\end{array}$ \\
\hline Employment status & $\begin{array}{l}\text { Employed full or part } \\
\text { time vs unemployed }\end{array}$ & 0.449 & - & 0.388 & - & 0.817 & - \\
\hline Atypical depression & $\begin{array}{l}\text { Defined by IDS-SR } \\
\text { criteria }\end{array}$ & 0.451 & - & 0.267 & - & 0.803 & - \\
\hline \multicolumn{8}{|l|}{ Continuous } \\
\hline $\begin{array}{l}\text { Baseline symptom } \\
\text { severity }\end{array}$ & $\begin{array}{l}\text { MADRS total score } \\
\text { at baseline }\end{array}$ & 0.037 & $\begin{array}{l}\text { Superior } \\
\text { outcome for } \\
\text { higher baseline } \\
\text { symptom } \\
\text { severity } \\
(r=-0.17)\end{array}$ & 0.433 & - & 0.024 & $\begin{array}{l}\text { Superior outcome } \\
\text { for higher baseline } \\
\text { symptom severity } \\
(r=-0.25)\end{array}$ \\
\hline $\begin{array}{l}\text { Baseline motor } \\
\text { threshold }\end{array}$ & $\begin{array}{l}\text { Motor threshold (\% } \\
\text { machine output) at } \\
\text { baseline }\end{array}$ & 0.563 & - & 0.054 & $\begin{array}{l}\text { Superior outcome } \\
\text { for lower baseline } \\
\text { motor threshold } \\
(r=+0.23)\end{array}$ & 0.829 & - \\
\hline
\end{tabular}

Variables indicated in bold demonstrated a significant main effect for the predictor variable within the treatment group specified $(P<0.10)$.

- No statistically different benefit at the specified level for the indicated treatment group.

Please see text for further discussion of results and direction of effect on outcome. 
Table 4 Summary of Demographic Characteristics, Illness Course and Symptom Severity of Patients with One vs More Than One Adequate Antidepressant Treatment in Current Episode (Randomized Controlled Trial)

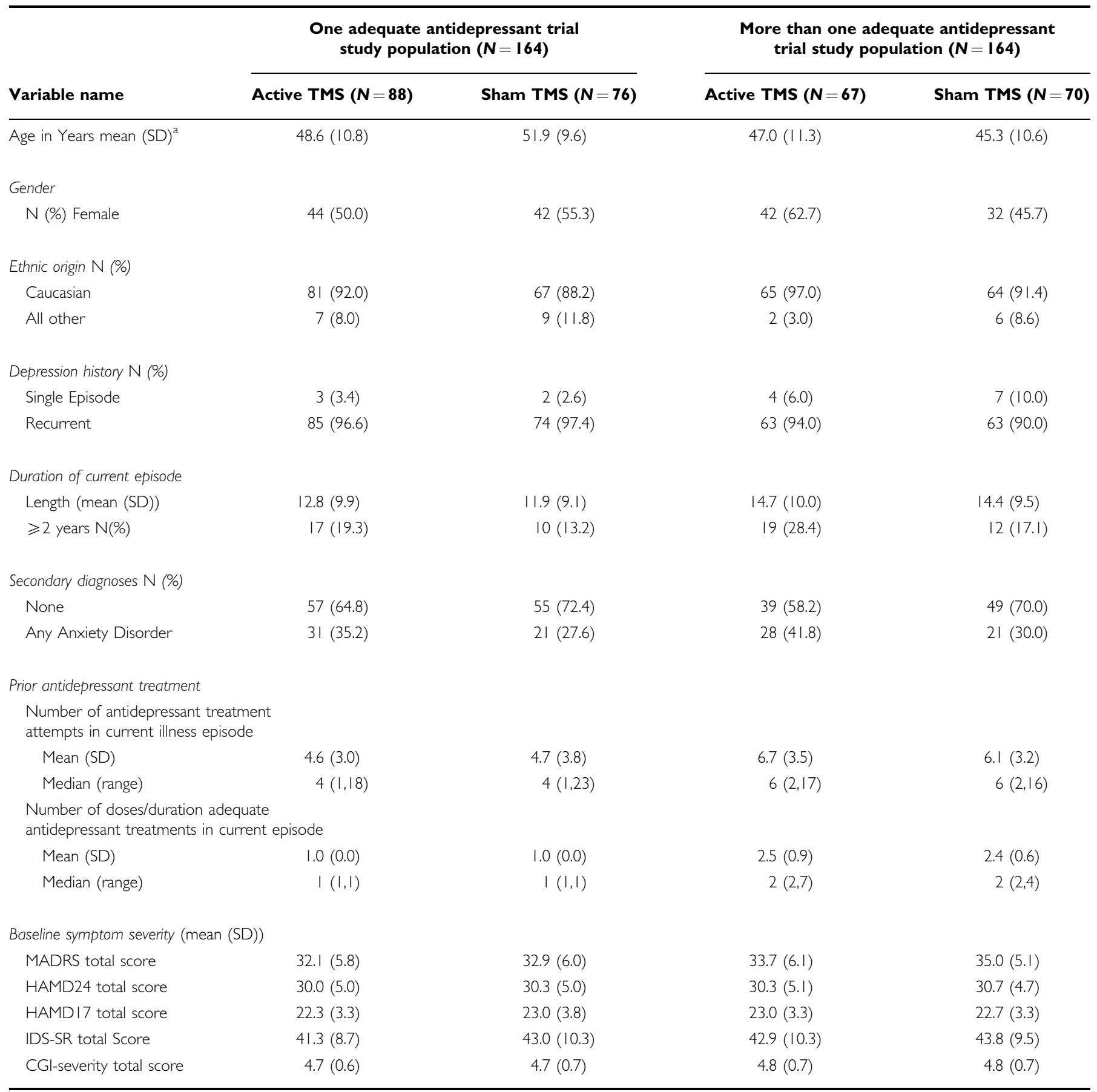

All other comparisons not significant ( $p>0.05)$.

${ }^{a} p=0.039$ for comparison of Active TMS vs Sham TMS within One Adequate Antidepressant population.

subsequently crossed over to open-label TMS showed the same effect of medication resistance, further supporting the importance of this variable in response prediction. The finding that TMS was more effective in patients who have failed to respond to one adequate trial of antidepressant medications in the current episode has important implications for patient selection. Indeed, the effect size of TMS in patients who had failed to respond to one adequate medication trial in the current episode was 0.83 , a large effect size. This result compares favorably to reported effect sizes for antidepressant medications in populations where treatment resistance is not typically used as an inclusion criterion (Khan et al, 2003; Moncrieff et al, 1998, 2004), and to the anticipated efficacy of a second adequate trial of antidepressant medications after a first failed adequate trial (Rush et al, 2006). Other clinical variables associated with improved response were the absence of a comorbid anxiety disorder and a higher baseline depression severity (Sham to TMS group only), and female gender and a shorter illness duration (Extended Active TMS group only). 
Table 5 Summary of Demographic Characteristics, Illness Course and Symptom Severity of Patients with One vs More Than One Adequate Antidepressant Treatment in Current Episode (Open Label Trial)

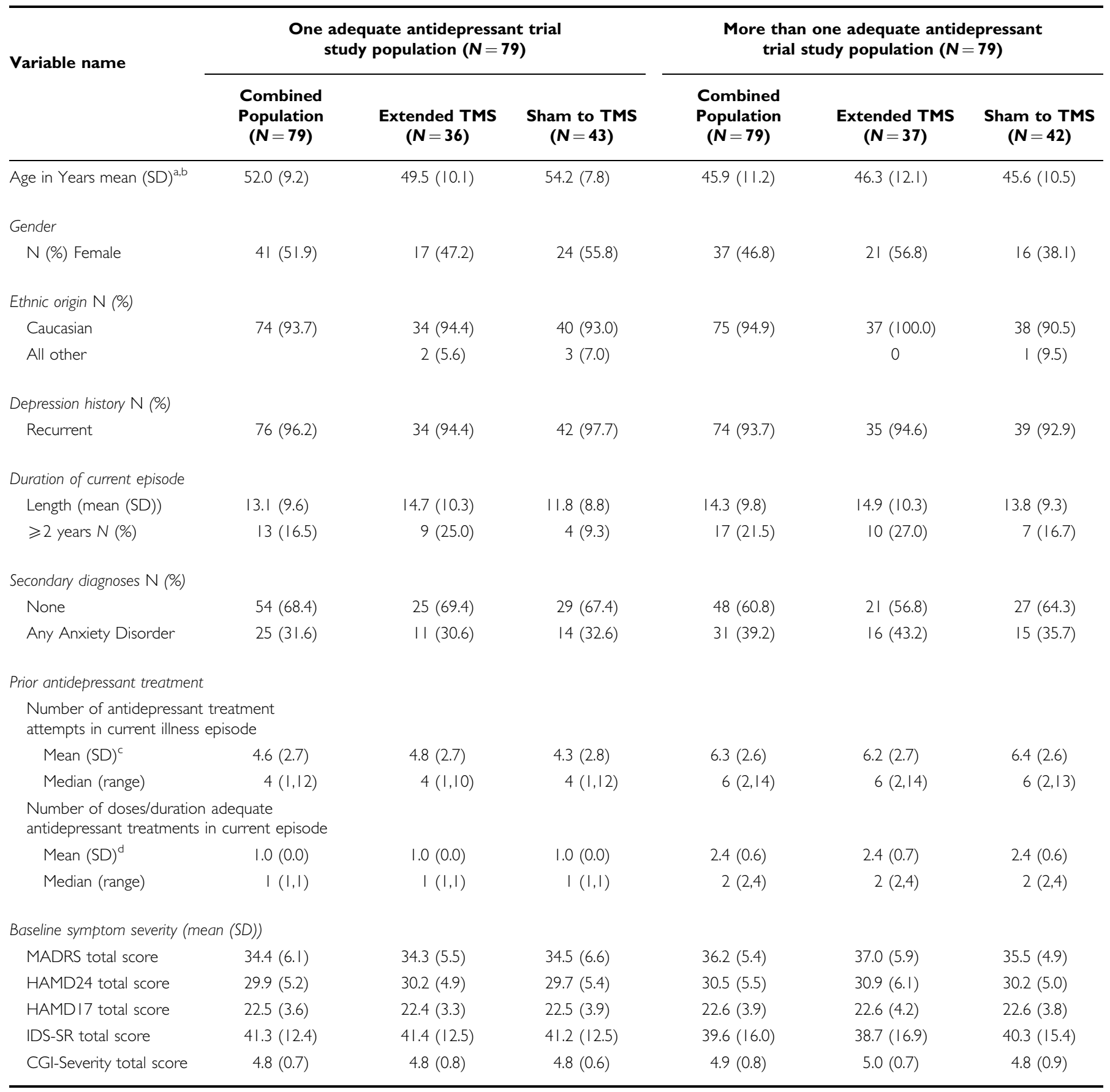

All other comparisons not significant ( $p>0.05$ ).

${ }^{a} p=0.023$ for comparison of Extended Active TMS vs Sham to TMS within the One Adequate Antidepressant population.

${ }^{b} p=0.0003$ for comparison of Combined Populations between One vs More Than One Antidepressant population.

$c_{p}<0.000$ I for comparison of Combined Populations between One vs More Than One Antidepressant population.

$\mathrm{d}_{p}<0.000$ I for comparison of Combined Populations between One vs More Than One Antidepressant population.

The absence of a relationship between treatment resistance and clinical outcome in the Extended Active TMS group is worth comment. To enter this phase of the study, patients had to have failed to receive meaningful clinical benefit from at least 4 weeks of active TMS. Therefore, at this point in the study the ATHF 1 group had now failed to receive clinical benefit from both one adequate antidepressant trial before study entry as well as a prospective controlled trial of active TMS treatment, indicating a higher degree of prospectively demonstrated treatment resistance, that may have obscured the effect of treatment resistance on outcome. The Extended Active TMS group also was more likely to have a current episode of greater than 2 years in duration than the Sham to TMS group, further complicating the comparison. 
We failed to replicate prior reports that age was a negative predictor of outcome (Figiel et al, 1998; Fregni et al, 2006; Manes et al, 2001; Mosimann et al, 2002, 2004; Su et al, 2005). Notably, patients that were $\geqslant 55$ showed a similar response as younger patients. Although our age cutoff of 70 may have affected our ability to detect an age effect, it is also possible that the longer course of TMS (at least 4 weeks) provided in this study was more effective in achieving response in older patients than the 1-2 weeks provided in the previous trials that reported an age effect (Figiel et al, 1998; Fregni et al, 2006; Manes et al, 2001; Mosimann et al, 2002, 2004; Su et al, 2005). There are suggestions that a subset of older patients demonstrate a slower trajectory of response, thereby benefiting from longer antidepressant medication trials (Gildengers et al, 2005). The same might hold true for TMS as well. Furthermore, the stimulation intensity of $120 \%$ of MT used in this trial may be able to overcome small amounts of atrophy that may be present in elderly patients potentially affecting outcome. Indeed, in the one study to examine this with MRI, an intensity of $117 \%$ MT would have been able to deliver a dose equivalent to MT in all depressed elders studied (Nahas et al, 2004).

Limitations of this study include the fact that only one dosage of TMS was examined. These results may not necessarily generalize to other TMS dosage and delivery paradigms. The sample studied here did not include certain clinical features that have been suggested by some investigators to be associated with reduced likelihood of clinical benefit with TMS, including psychotic subtype, and age over 70. It is worth noting that approximately 100 patients with age $\geqslant 55$ were included in this trial. Treatment resistance was also capped by protocol to no more than four adequate treatment failures in the current episode. Therefore specific conclusions regarding these factors cannot be made from this data set. The sample also limited the inclusion criteria in the duration of current episode (capped at 3 years). Other neurobiological factors that have been thought to be associated with clinical response were not measured. For example, studies have suggested that certain genetic polymorphisms (Baghai et al, 2004; McMahon et al, 2006; Paddock et al, 2007) and patterns of brain metabolic activity (eg hypermetabolism in the rostral cingulate; Mayberg et al, 1997; Teneback et al, 1999) may be associated with the likelihood of antidepressant response. Considering that TMS is a focal intervention, variation in patterns of regional brain activity may be especially relevant for likelihood of response to TMS as suggested by Kimbrell et al (1999). Finally, this study did not collect MRI scans to allow measurement of distance from the coil to the nearest cortex and distance of the coil from the target in left DLPFC.

This study suggests that patients with unipolar depression who have failed one adequate medication trial in the current episode are more likely to have a therapeutic response to $10 \mathrm{~Hz}$ TMS delivered to the left DLPFC using the treatment schedule used in this study than those who have failed 2-4 trials. These results may be useful in guiding patient selection, for the design of future studies on the clinical efficacy of TMS, and also in defining the appropriate phase of illness for which TMS would be most effective.

\section{ACKNOWLEDGEMENTS}

We thank the patients who participated in this clinical trial. In addition, we acknowledge the members of the Neuronetics TMS Steering Committee (Alan F Schatzberg, Stanford University; Mark S George, Medical University of South Carolina; Harold A Sackeim, Columbia University; Mark A Demitrack, Neuronetics Inc.) and the principal investigators who were members of the Neuronetics TMS Study Group and their staff; Scott Aaronson, Sheppard Pratt Health System; David Avery, University of Washington Medical Center; Randolph Canterbury, University of Virginia; Zafiris J Daskalakis, Centre for Addiction and Mental Health; James Ferguson, Radiant Research; Paul Fitzgerald, The Alfred Psychiatry Research Centre; William Gilmer, Northwestern University; Rosben Guiterrez, PsyCare Inc.; Mustafa Husain, University of Texas-Southwestern Medical Center; Keith Isenberg, Washington University School of Medicine; Philip G Janicak, Rush University Medical Center; Andrew Krystal, Duke University Medical Center; Sarah H Lisanby, New York State Psychiatric Institute/Columbia University; Colleen Loo, University of New South Wales; Daniel Maixner, University of Michigan Medical Center; Lauren Marangell, Baylor College of Medicine; William McDonald, Emory University; Ziad Nahas, Medical University of South Carolina; John P O'Reardon, University of Pennsylvania; Elliot Richelson, Shirlene Sampson, Mayo Clinic; Peter Rosenquist, Wake Forest University Health Sciences; Brent Solvason, Stanford University. This study was supported by a grant from Neuronetics Inc.

\section{DISCLOSURE/CONFLICT OF INTEREST}

The authors declare that this work was funded by a research grant from Neuronetics (the manufacturer of the device used in this trial). Each author received a research grant from Neuronetics to conduct this trial.

Drs Canterbury, Daskalakis, and Rosenquist declare that, except for income received from their primary employer and except for the research grant from Neuronetics to conduct this trial, no financial support or compensation has been received from any individual or corporate entity over the past 3 years for research or professional service and there are no personal financial holdings that could be perceived as constituting a potential conflict of interest. Information regarding compensation over the past 3 years for the remaining authors is provided below:

Dr Aaronson reports having received research support from GlaxoSmithKline, Dalio Family Foundation, Cephalon; consulting honoraria from Eli Lilly; Speaker Bureau honoraria from Eli Lilly, AstraZeneca, GlaxoSmithKline, Bristol-Myers Squibb, Cyberonics; and Clinical Trials support from Eli Lilly, Pfizer, AstraZeneca, Cyberonics, Bristol-Myers Squibb, Myriad, Novartis, Sanofi-Aventis, Organon, Boehringer Ingelheim.

Dr George reports the following relationships with pharmaceutical companies: Argolyn (consultant-past), Aventis (consultant-past), Bristol-Meyers Squibb (consultant), Cortex (Clinical Trial Research Grant-past), DarPharma (Imaging Research Grant), GlaxoSmithKline (Imaging Research Grant and Speakers Bureau), Janssen 
Pharmaceuticals (Imaging Research Grant and Speakers Bureau - past), Jazz Pharmaceuticals (research grant/consultant), Lilly Pharmaceuticals (Imaging Research Grant and Speakers Bureau-past), Parke-Davis (Imaging Research Grant - past, Speakers Bureau, consultant), Solvay/ Duphar (Imaging Research Grant - past). Dr George also reports the following relationships with imaging and stimulation device companies: Aspect Medical (DSMB member, consultant), Brainsway (consultant, research grant), Brainsonix (advisory board-unpaid), Cephos (advisory board - unpaid and research grant), Cyberonics Inc. (Clinical Research Grants, Imaging Grant, Speakers Bureau, Depression Advisory Board, Mechanisms of Action Advisory Board), Dantec (Medtronic) (Formal Research Collaborations on TMS and DBS), Dupont Pharma (Imaging Research Grant-past), Mediphysics/Amersham (Imaging Research Grant, Speakers Bureau-past), Neotonus (now Neuronetics) (Clinical Research Grant, consultant-past, advisory board-unpaid), NeuroPace (advisory board), Picker International (now Phillips) (Formal Research Collaboration on MRI - past). Dr George reports no equity ownership in any device or pharmaceutical company. His total industry-related compensation is $<10 \%$ of his university salary. MUSC has filed eight patents or invention disclosures in his name regarding brain imaging and stimulation devices.

Dr Gilmer has received research support from, served in advisory capacity to, or received speakers honoraria from Abbott Laboratories; Aspect Medical Systems; AstraZeneca; Bristol-Myers Squibb; Forest Pharmaceuticals; GlaxoSmithKline; Janssen Pharmaceutica; National Institute of Mental Health, Neuronetics; Northwestern University; Novartis; and Pfizer.

Dr Gutierrez has received financial support for clinical research from Eli Lilly and GlaxoSmithKline pharmaceutical companies.

Dr Husain has received research support from NIMH, Stanley Medical Research Institute, Cyberonics, and Magstim Company. Dr Husain serves on the Speakers Bureau for AstraZeneca, Bristol-Meyers Squibb, and Abbott Labs.

Dr Krystal has received patent royalties to Duke University from the MECTA Corp; research support from NIH, Sanofi-Aventis, Cephalon, GlaxoSmithKline, Merck, Neurocrine, Pfizer, Sepracor, Somaxon, Takeda, Transcept, Respironics, Evotec, Astellas; consulting fees from Actelion, Arena, Astellas, Axiom, AstraZeneca, Bristol-Myers Squibb, Cephalon, Eli Lilly, GlaxoSmithKline, Jazz, Johnson and Johnson, King, Merck, Neurocrine, Neurogen, Novartis, Organon, Pfizer, Respironics, Sanofi-Aventis, Sepracor, Somaxon, Takeda, Transcept, Astellas, Research Triangle Institute; and Speakers Bureau fees from Sleep Medicine Education Institute, Sepracor, and Sanofi-Aventis.

Dr Lisanby has received research support from Magstim Company, Neuronetics, Cyberonics, NIH, AFAR, NARSAD, Stanley Medical Research Foundation, DARPA, NYSTAR, Advanced Neuromodulation Systems; serves as chair of the DSMB for Northstar Neuroscience; has receive speakers honoraria from Magstim (past), Cyberonics (past), and the Kinetics Foundation (past); served as a member of the Defense Sciences Study Group (supported by DARPA and the Institute for Defense Analysis); and serves on an NIH Study Section. Columbia University has filed a patent application for novel TMS technology developed in $\mathrm{Dr}$ Lisanby's laboratory, not the device presented here.

Dr Maixner has received compensation for Speakers Bureau consultation from Pfizer, Bristol-Myers Squibb, Janssen, AstraZeneca, and Cyberonics.

Dr Marangell has received grant/research support from Bristol-Myers Squibb, Eli Lilly, Cyberonics, Neuronetics, Stanley Foundation, Aspect Medical Systems, and SanofiAventis. She has received consultant/honoraria fees from Eli Lilly, GlaxoSmithKline, Cyberonics, Pfizer, Medtronic, Forest, Aspect Medical Systems, and Novartis.

Dr Richelson has served as a consultant for Janssen, Eli Lilly, Takeda, Lundbeck, and Somaxon; and received grant/ research support from Janssen and Neuronetics.

Dr Sackeim has received compensation from Cyberonics, Eli Lilly, Mecta, Magstim, Neuronetics, Novartis, NeuroPace, and Pfizer. He serves as a consultant to Cyberonics, MECTA, and Neuronetics.

\section{REFERENCES}

Avery DH, Holtzheimer III PE, Fawaz W, Russo J, Neumaier J, Dunner DL et al (2006). A controlled study of repetitive transcranial magnetic stimulation in medication-resistant major depression. Biol Psychiatry 59: 187-194.

Avery DH, Isenberg KE, Sampson S, Janicak PG, Lisanby SH, Maixner DF et al (2008). Transcranial magnetic stimulation in the acute treatment of major depression: clinical response in an open-label extension trial. J Clin Psychiatry 69: 441-451.

Baghai TC, Schule C, Zill P, Deiml T, Eser D, Zwanzger P et al (2004). The angiotensin I converting enzyme insertion/deletion polymorphism influences therapeutic outcome in major depressed women, but not in men. Neurosci Lett 363: 38-42.

Boutros NN, Gueorguieva R, Hoffman RE, Oren DA, Feingold A, Berman RM (2002). Lack of a therapeutic effect of a 2-week subthreshold transcranial magnetic stimulation course for treatment-resistant depression. Psychiatry Res 113: 245-254.

Brakemeier EL, Luborzewski A, Danker-Hopfe H, Kathmann N, Bajbouj M (2007). Positive predictors for antidepressive response to prefrontal repetitive transcranial magnetic stimulation (rTMS). J Psychiatr Res 41: 395-403.

Burt T, Lisanby SH, Sackeim HA (2002). Neuropsychiatric applications of transcranial magnetic stimulation: a meta analysis. Int J Neuropsychopharmacol 5: 73-103.

Cohen CI, Amassian VE, Akande B, Maccabee PJ (2003). The efficacy and safety of bilateral rTMS in medication-resistant depression. J Clin Psychiatry 64: 613-614.

Davey K, Epstein CM (2000). Magnetic stimulation coil and circuit design. IEEE Trans Biomed Eng 47: 1493-1499.

Demitrack M, Lisanby SH (2008). Methodological issues in clinical trial design for TMS. In: Wassermann EM, Epstein C, Ziemann U, Walsh V, Paus T, Lisanby SH (eds). The Oxford Handbook of Transcranial Stimulation. Oxford University Press: New York. pp 621-631.

Dew MA, Reynolds III CF, Houck PR, Hall M, Buysse DJ, Frank E et al (1997). Temporal profiles of the course of depression during treatment. Predictors of pathways toward recovery in the elderly. [see comment]. Arch Gen Psychiatry 54: 1016-1024.

Figiel GS, Epstein C, McDonald WM, Amazon-Leece J, Figiel L, Saldivia A et al (1998). The use of rapid-rate transcranial magnetic stimulation (rTMS) in refractory depressed patients. J Neuropsychiatry Clin Neurosci 10: 20-25.

Fitzgerald PB, Brown TL, Marston NA, Daskalakis ZJ, De Castella A, Kulkarni J (2003). Transcranial magnetic stimulation in the 
treatment of depression: a double-blind, placebo-controlled trial. Arch Gen Psychiatry 60: 1002-1008.

Fitzgerald PB, Huntsman S, Gunewardene R, Kulkarni J, Daskalakis ZJ (2006). A randomized trial of low-frequency right-prefrontal-cortex transcranial magnetic stimulation as augmentation in treatment-resistant major depression. [see comment]. Int J Neuropsychopharmacol 9: 655-666.

Fregni F, Marcolin MA, Myczkowski M, Amiaz R, Hasey G, Rumi DO et al (2006). Predictors of antidepressant response in clinical trials of transcranial magnetic stimulation. [see comment]. Int J Neuropsychopharmacol 9: 641-654.

Gershon AA, Dannon PN, Grunhaus L (2003). Transcranial magnetic stimulation in the treatment of depression. Am J Psychiatry 160: 835-845.

Gildengers AG, Houck PR, Mulsant BH, Dew MA, Aizenstein HJ, Jones BL et al (2005). Trajectories of treatment response in latelife depression: psychosocial and clinical correlates. J Clin Psychopharmacol 25: S8-13.

Gross M, Nakamura L, Pascual-Leone A, Fregni F (2007). Has repetitive transcranial magnetic stimulation (rTMS) treatment for depression improved? A systematic review and meta-analysis comparing the recent $v s$ the earlier rTMS studies. Acta Psychiatr Scand 116: 165-173.

Hansen PE, Videbech P, Clemmensen K, Sturlason R, Jensen HM, Vestergaard P (2004). Repetitive transcranial magnetic stimulation as add-on antidepressant treatment. The applicability of the method in a clinical setting. Nord J Psychiatry 58: 455-457.

Hausmann A, Kemmler G, Walpoth M, Mechtcheriakov S, KramerReinstadler K, Lechner T et al (2004). No benefit derived from repetitive transcranial magnetic stimulation in depression: a prospective, single centre, randomised, double blind, sham controlled 'add on' trial. J Neurol Neurosurg Psychiatry 75: 320-322.

Hirschfeld RM, Klerman GL, Andreasen NC, Clayton PJ, Keller MB (1986). Psycho-social predictors of chronicity in depressed patients. Br J Psychiatry 148: 648-654.

Holtzheimer III PE, Russo J, Avery DH (2001). A meta-analysis of repetitive transcranial magnetic stimulation in the treatment of depression. [erratum appears in Psychopharmacol Bull 2003 Spring;37(2):5]. Psychopharmacol Bull 35: 149-169.

Holtzheimer III PE, Russo J, Claypoole KH, Roy-Byrne P, Avery DH (2004). Shorter duration of depressive episode may predict response to repetitive transcranial magnetic stimulation. Depress Anxiety 19: 24-30.

Janicak P, O’Reardon J, Sampson S, Husain MM, Lisanby SH, Rado JT et al (2008). Transcranial magnetic stimulation in the treatment of major depressive disorder: a comprehensive summary of safety experience from acute exposure, extended exposure and reintroduction treatment. J Clin Psychiatry 69: 222-232.

Kammer T, Beck S, Erb M, Grodd W (2001a). The influence of current direction on phosphene thresholds evoked by transcranial magnetic stimulation. Clin Neurophysiol 112: 2015-2021.

Kammer T, Beck S, Thielscher A, Laubis-Herrmann U, Topka H (2001b). Motor thresholds in humans: a transcranial magnetic stimulation study comparing different pulse waveforms, current directions and stimulator types. Clin Neurophysiol 112: 250-258.

Keller MB, Klerman GL, Lavori PW, Coryell W, Endicott J, Taylor J (1984). Long-term outcome of episodes of major depression. Clinical and public health significance. JAMA 252: 788-792.

Keller MB, Lavori PW, Rice J, Coryell W, Hirschfeld RM (1986). The persistent risk of chronicity in recurrent episodes of nonbipolar major depressive disorder: a prospective follow-up. Am J Psychiatry 143: 24-28.

Khan A, Khan SR, Walens G, Kolts R, Giller EL (2003). Frequency of positive studies among fixed and flexible dose antidepressant clinical trials: an analysis of the food and drug administration summary basis of approval reports. Neuropsychopharmacology 28: $552-557$.

Kimbrell TA, Little JT, Dunn RT, Frye MA, Greenberg BD, Wassermann EM et al (1999). Frequency dependence of antidepressant response to left prefrontal repetitive transcranial magnetic stimulation (rTMS) as a function of baseline cerebral glucose metabolism. Biol Psychiatry 46: 1603-1613.

Kozel FA, Nahas Z, deBrux C, Molloy M, Lorberbaum JP, Bohning $\mathrm{D}$ et al (2000). How coil-cortex distance relates to age, motor threshold, and antidepressant response to repetitive transcranial magnetic stimulation. J Neuropsychiatry Clin Neurosci 12: 376-384.

Loo C, Mitchell P, Sachdev P, McDarmont B, Parker G, Gandevia S (1999). Double-blind controlled investigation of transcranial magnetic stimulation for the treatment of resistant major depression. Am J Psychiatry 156: 946-948.

Loo CK, Mitchell PB, Croker VM, Malhi GS, Wen W, Gandevia SC et al (2003). Double-blind controlled investigation of bilateral prefrontal transcranial magnetic stimulation for the treatment of resistant major depression. [see comment]. Psychol Med 33: 33-40.

Maccabee PJ, Nagarajan SS, Amassian VE, Durand DM, Szabo AZ, Ahad $\mathrm{AB}$ et al (1998). Influence of pulse sequence, polarity and amplitude on magnetic stimulation of human and porcine peripheral nerve. J Physiol 513: 571-585.

Manes F, Jorge R, Morcuende M, Yamada T, Paradiso S, Robinson RG (2001). A controlled study of repetitive transcranial magnetic stimulation as a treatment of depression in the elderly. Int Psychogeriatr 13: 225-231.

Martin JL, Barbanoj MJ, Schlaepfer TE, Thompson E, Perez V, Kulisevsky J (2003). Repetitive transcranial magnetic stimulation for the treatment of depression. Systematic review and metaanalysis. [see comment]. Br J Psychiatry 182: 480-491.

Mayberg HS, Brannan SK, Mahurin RK, Jerabek PA, Brickman JS, Tekell JL et al (1997). Cingulate function in depression: a potential predictor of treatment response. Neuroreport 8: 1057-1061.

McMahon FJ, Buervenich S, Charney D, Lipsky R, Rush AJ, Wilson $\mathrm{AF}$ et al (2006). Variation in the gene encoding the serotonin $2 \mathrm{~A}$ receptor is associated with outcome of antidepressant treatment. Am J Hum Genet 78: 804-814.

Mitchell PB, Loo CK (2006). Transcranial magnetic stimulation for depression. [see comment]. Aust N Z J Psychiatry 40: 406-413.

Moncrieff J, Wessely S, Hardy R (1998). Meta-analysis of trials comparing antidepressants with active placebos. [see comment]. Br J Psychiatry 172: 227-231; discussion 232-224.

Moncrieff J, Wessely S, Hardy R (2004). Active placebos vs antidepressants for depression. [update of Cochrane Database Syst Rev 2001; CD003012; PMID: 11406060]. Cochrane Database Syst Rev CD003012.

Mosimann UP, Marre SC, Werlen S, Schmitt W, Hess CW, Fisch HU et al (2002). Antidepressant effects of repetitive transcranial magnetic stimulation in the elderly: correlation between effect size and coil-cortex distance. Arch Gen Psychiatry 59: 560-561.

Mosimann UP, Schmitt W, Greenberg BD, Kosel M, Muri RM, Berkhoff $\mathrm{M}$ et al (2004). Repetitive transcranial magnetic stimulation: a putative add-on treatment for major depression in elderly patients. Psychiatry Res 126: 123-133.

Nahas Z, Li X, Kozel FA, Mirzki D, Memon M, Miller K et al (2004). Safety and benefits of distance-adjusted prefrontal transcranial magnetic stimulation in depressed patients 55-75 years of age: a pilot study. Depress Anxiety 19: 249-256.

Nahas Z, Teneback CC, Kozel A, Speer AM, DeBrux C, Molloy M et al (2001). Brain effects of TMS delivered over prefrontal cortex in depressed adults: role of stimulation frequency and coilcortex distance. J Neuropsychiatry Clin Neurosci 13: 459-470.

O'Reardon JP, Solvason HB, Janicak PG, Sampson S, Isenberg KE, Nahas Z et al (2007). Efficacy and safety of transcranial magnetic 
stimulation in the acute treatment of major depression: a multisite randomized controlled trial. Biol Psychiatry 62: 1208-1216.

Padberg F, Zwanzger P, Keck ME, Kathmann N, Mikhaiel P, Ella R et al (2002). Repetitive transcranial magnetic stimulation (rTMS) in major depression: relation between efficacy and stimulation intensity. Neuropsychopharmacology 27: 638-645.

Paddock S, Laje G, Charney D, Rush A, Wilson A, Sorant A et al (2007). Association of GRIK4 with outcome of antidepressant treatment in the $\mathrm{STAR}^{\star} \mathrm{D}$ cohort. Am J Psychiatry 164: $1181-1188$

Paykel ES (1972). Depressive typologies and response to amitriptyline. Br J Psychiatry 120: 147-156.

Prudic J, Haskett RF, Mulsant B, Malone KM, Pettinati HM, Stephens S et al (1996a). Resistance to antidepressant medications and short-term clinical response to ECT. Am J Psychiatry 153: 985-992.

Prudic J, Haskett RF, Mulsant B, Malone KM, Pettinati HM, Stephens $S$ et al (1996b). Resistance to antidepressant medications and short-term clinical response to ECT. [see comment]. Am J Psychiatry 153: 985-992.

Rush AJ, Trivedi MH, Wisniewski SR, Nierenberg AA, Stewart JW, Warden D et al (2006). Acute and longer-term outcomes in depressed outpatients requiring one or several treatment steps: a STAR*D report. Am J Psychiatry 163: 1905-1917.
Sachdev PS, McBride R, Loo C, Mitchell PM, Malhi GS, Croker V (2002). Effects of different frequencies of transcranial magnetic stimulation (TMS) on the forced swim test model of depression in rats. Biol Psychiatry 51: 474-479.

Simpson GM, Lee JH, Cuculic Z, Kellner R (1976). Two dosages of imipramine in hospitalized endogenous and neurotic depressives. Arch Gen Psychiatry 33: 1093-1102.

Su TP, Huang CC, Wei IH (2005). Add-on rTMS for medicationresistant depression: a randomized, double-blind, sham-controlled trial in Chinese patients. J Clin Psychiatry 66: 930-937.

Teneback CC, Nahas Z, Speer AM, Molloy M, Stallings LE, Spicer $\mathrm{KM}$ et al (1999). Changes in prefrontal cortex and paralimbic activity in depression following two weeks of daily left prefrontal TMS. J Neuropsychiatry Clin Neurosci 11: 426-435.

Thielscher A, Kammer T (2004). Electric field properties of two commercial figure- 8 coils in TMS: calculation of focality and efficiency. Clin Neurophysiol 115: 1697-1708.

Trivedi MH, Rush AJ, Wisniewski SR, Nierenberg AA, Warden D, Ritz L et al (2006). Evaluation of outcomes with citalopram for depression using measurement-based care in $S T A R^{*} D$ : implications for clinical practice. [see comment]. Am J Psychiatry 163 28-40.

Wassermann EM (2002). Variation in the response to transcranial magnetic brain stimulation in the general population. Clin Neurophysiol 113: 1165-1171. 